\title{
Factors Affecting Uptake and Utilization of Insecticide Treated Net Among Women of Reproductive Age (15 - 49 years) Group Attending Antenatal Clinics in Nasarawa State Nigeria
}

\author{
Hassan Ikrama ${ }^{1}$ Gonji Thomas ${ }^{2}$ Olorunsogo Ayodeji ${ }^{2} \quad$ Michael Anazodo $^{1} \quad$ Babatunde Joseph $^{1}$ \\ Odonye Eselema Caleb ${ }^{1} \quad$ Sasetu Stephen $^{3} \quad$ Lawal Abdulmumuni Ahmed $^{4}$ Adedayo Adeyemi ${ }^{1}$ \\ Bako Ishiaku $^{5} \quad$ Bello Surajudeen Oyeleke $6^{*}$ \\ 1.Department of Community Medicine, Dalhatu Araf Specialist Hospital, Lafia Nasarawa State Nigeria \\ 2.Department of Medical Services, Hospitals Management Board, Nasarawa State Nigeria \\ 3.Department of Planning Research and Statistics \\ Nasarawa Primary Healthcare Development Agency, Nasarawa State Nigeria \\ 4.Department of Anatomy, Federal University Lafia, Nasarawa State Nigeria \\ 5.Department of Community Medicine, Benue State University Teaching Hospital, Makurdi Benue State \\ 6.Department of Paediatrics, Dalhatu Araf Specialist Hospital, Lafia Nasarawa State Nigeria
}

\begin{abstract}
Background: Vector control is the main path to preventing and reducing malaria transmission. The ownership and use of Insecticide-Treated Nets (ITNs) is the core vector control method and a proven intervention for the control and elimination of malaria in several malaria-endemic countries. This study determined the factors affecting the uptake and utilization of ITN by women in their reproductive age group in Nasarawa State Nigeria.

Methods: A descriptive cross sectional study among women of reproductive age group (15 - 49 years) attending Ante Natal Clinic at the Dalhatu Araf Specialist Hospital Lafia, General Hospital Akwanga and Medical Centre Mararaba Gurku in Nasarawa State Nigeria. An interviewer administered questionnaire was used after obtaining an informed consent. Ethical approval was gotten from the state research ethics committee. Data analysis was done using SPSS version 23.0.

Results: The mean age of this study population was $27.9 \pm 10.6$ years. Of the total number of 772 participants in this study, a larger chunk of 707 (91.6\%) have heard of insecticide treated net. In addition, most 538 (69.7\%) participants said healthcare workers emphasizes the use of insecticide treated net during their antenatal care visits. More than half of the participants, 432 (56.0\%) owned an ITN at home. Utilization of insecticide treated nets showed that, 451 (58.4\%) sleeps under an insecticide treated net, with $334(74.1 \%)$ of these sleeping under it daily. Reasons for not using ITN for some were; due to heat $137(30.4 \%)$, due to smell $83(18.3 \%)$ and others for no good reason $86(19.1 \%)$ respectively. Beliefs about usefulness of ITN showed $320(71.0 \%)$ felt it is very good and useful in preventing malaria.

Conclusions: Most participants are aware of ITN. More than half owned (56\%) and sleeps (58.4\%) under the ITN. About $71 \%$ believed ITN is useful in preventing mosquito bites and malaria. Reasons for declining using ITN among some were due to the ITN's heat and smell. While more than two-third felt ITN is useful in preventing mosquito bites and malaria.
\end{abstract}

Keywords: Factors, Insecticide Treated Nets, Uptake, Utilization.

DOI: $10.7176 / \mathrm{JHMN} / 92-06$

Publication date:August $31^{\text {st }} 2021$

\section{Introduction}

Insect borne diseases such as malaria, yellow fever, dengue fever, sleeping sickness, filariasis etc, have always been a global public health issue with malaria incidence being the commonest of all. ${ }^{1}$ The burden of these diseases is highest in tropical and subtropical areas and they disproportionately affect the poorest populations. ${ }^{2}$ Since 2014, major outbreaks of dengue, malaria, chikungunya, yellow fever and Zika have afflicted populations, claimed lives and overwhelmed health systems in many countries. ${ }^{3}$

Malaria, a major challenge here occurs mostly in the poor tropical and subtropical areas of the world. ${ }^{4}$ It is the leading cause of morbidity and mortality in many developing countries especially in Sub-Saharan Africa, where under-five children and pregnant women are the groups mostly affected. ${ }^{3,5}$ Malaria is a life-threatening disease caused by parasites that are transmitted to people through the bites of infected female Anopheles mosquitoes. ${ }^{4,6}$ Transmission is more intense in places where the mosquito lifespan is longer (so that the parasite has time to complete its development inside the mosquito) and where it prefers to bite humans rather than other animals. ${ }^{2,7}$ The long lifespan and strong human-biting habit of the African vector species is the main reason why approximately $90 \%$ of the world's malaria cases are in Africa by World Health Organization (WHO). ${ }^{1}$ Transmission also depends on certain climatic and environmental conditions such as rainfall patterns, temperature, humidity, presence of bushy areas and stagnant waters around the home which encourage the 
breeding of these mosquitoes. ${ }^{5,8}$ In many places, transmission is seasonal, with the peak during and just after the rainy season. Human immunity is also another important factor. ${ }^{9}$ The estimated number of malaria cases stood at 217 million in 2016 and rose to 219 million in 2017. ${ }^{1.10}$ Children under 5 years of age are the most vulnerable group affected and accounted for $61 \%(266,000)$ of all malaria deaths worldwide. ${ }^{10}$ The effects of malaria are also strong among pregnant women, for whom malaria may cause maternal anaemia, preterm delivery, and low birth weight. ${ }^{11}$ African region continues to carry a disproportionately high share of the global malaria burden. ${ }^{12}$ They (African countries) accounted for nearly half of all malaria cases worldwide with Nigeria contributing $25 \% .^{1}$ In Nigeria, malaria is responsible for $30 \%$ of the under-five mortality and $11 \%$ of maternal mortality rate. ${ }^{3,10}$

Malaria is preventable and curable. Early diagnosis and treatment of malaria reduces disease and prevents deaths. It also contributes to reducing malaria transmission. The best available treatment, particularly for $P$. falciparum malaria, is artemisinin-based combination therapy (ACT). ${ }^{13}$

However, Vector control is the main path to preventing and reducing malaria transmission. ${ }^{9}$ The use of Insecticide-Treated Nets (ITNs) among other forms such as Residual Spraying is one of the core vector control methods for preventing malaria and other vector-borne diseases and has been shown to reduce malaria incidence by $50 \%$ in several malaria-endemic countries. ${ }^{10}$ Ownership and use of insecticide net is one of the proven interventions adopted by Roll Back Malaria (RBM) partners in Nigeria to stem the high incidence of malaria. ${ }^{1}$ The ITN programs depend to a much greater extent on the acceptance and active involvement of individuals and communities. The success or failure of ITN programs may in many cases be related to several human behavioural factors that affect coverage and proper usage. ${ }^{7,13}$ Factors contributing to the uptake and utilization of ITN in recent time need to be evaluated. This study therefore, seeks to assess caregivers' knowledge about ITNs, utilization of ITNs and factors influencing the uptake and use of ITNs among women of child bearing age in Dalhatu Araf Specialist Hospital.

\section{Justification for the Study}

Where ITN appear to fail, this is in many cases due to human behavioural factors related to coverage, proper and consistent use of ITNs. These human factors are underrated, not systematically monitored, or at least go underreported in many publications and reports. Also, no such study has been conducted in this locality. This study therefore seeks to evaluate the factors affecting the uptake and utilization of ITNs among women of child bearing age in Dalhatu Araf Specialist Hospital.

\section{Study Objectives}

1. To determine the current uptake and utilization of Insecticide Treated Nets among women of reproductive age (15-49years) group attending ANC in DASH.

2. To assess the knowledge and beliefs of caregivers towards the usage of ITNs.

\section{Methodology}

Study area

This was a hospital-based prospective cross-sectional study of women of reproductive age group (15 - 49 years) attending the antenatal clinics at the Dalhatu Araf Specialist Hospital Lafia (DASH), General Hospital Akwanga and Medical Centre Mararaba Gurku, all of Nasarawa State over three months period of January 2021 to March 2021. Dalhatu Araf Specialist Hospital is the only state owned tertiary hospital. It is located in Lafia, the state capital of Nasarawa State. The state is one of the six North-Central states. It has border with Federal Capital Territory Abuja, Benue, Kogi, Taraba, Plateau and Kaduna States respectively.

The State has three senatorial zones of Nasarawa South, North and West respectively. The DASH situated in Lafia representing Nasarawa South, General Hospital Akwanga representing Nasarawa North and the Medical Centre Mararaba Gurku representing Nasarawa West.

\section{Study design}

This is a prospective descriptive cross-sectional study.

\section{Sample size}

Sample size was calculated using the formula below:

$$
\mathrm{n}=\frac{\mathrm{Z}^{2} \mathrm{pq}}{\mathrm{d}^{2}}
$$

Where $\mathrm{n}=$ sample size

$\mathrm{Z}$ is standard normal deviation of 1.96

$\mathrm{p}$ is the prevalence which is $60 \%$ (Roll back malaria in Africa) 
$\mathrm{q}=1-\mathrm{p}$

$\mathrm{d}$ is the degree of accuracy desired usually set at $5 \%$.

Therefore

$$
\begin{aligned}
& \mathrm{n}=\frac{1.96^{2} \times 0.60 \times 0.4}{0.05^{2}} \\
& \mathrm{n}=369 \\
& \text { Non-response }=10 \%=\mathrm{n}=\frac{369}{100} \times \frac{10}{1}=36.9
\end{aligned}
$$

The study was conducted on sample size of 406

\section{Sampling method}

All women attending Ante Natal Clinic (ANC) that consented to the study during the period under review were recruited.

Inclusion criteria: all clients undergoing ante-natal care were enrolled during the period of study

Exclusion criteria: all clients who declined participation.

\section{Ethical consideration}

Ethical clearance was obtained from Research Ethics Committee of the State. Confidentiality of information collected was treated with utmost regards.

\section{Funding}

This study was funded by Saving One Million Lives, Programme For Result (P4R) Nasarawa state.

Data collection: Questionnaires were administered by researchers and three research assistants (one per site) to patient that met the inclusion criteria.

\section{Data analysis}

Data was analysed using SPSS (Statistical Package for the Social science) version 23.0. Frequencies and percentages were computed for categorical variables while means and standard deviation were determined for continuous variables. Results obtained after analysis are presented in tables and charts below. Significant $p$ is any value $<0.05$.

\section{Results}

\section{Socio-demographic characteristics of study participants}

The mean age of this study population is $27.9 \pm 10.6$ years. Of the total number of 772 participants in this multicentre study, 406 (52.6\%) were from DASH, 160 (20.7\%) were from General Hospital Akwanga and 206 (26.7\%) were from the Medical Centre Mararaba Gurku respectively. Most 760 (98.4\%) of the participants were married while $12(1.6 \%)$ were single pregnant women. An assessment of the educational attainment of participants in the study revealed, $339(43.8 \%)$ had tertiary education, $319(41.3 \%)$ had secondary education, $83(10.8 \%)$ had primary education and 32 (4.1\%) having no any form of formal education. Most of the respondent, $648(83.9 \%)$ reside in urban settings. A good number of the participants $325(42.1 \%)$ were either self employed running their business, $117(15.2 \%)$ were civil servants, $13(1.7 \%)$ were farmers, while $166(21.5 \%)$ had other engagements

\begin{tabular}{|c|c|c|}
\hline Variables & Frequencies n & Percentages $\%$ \\
\hline \multicolumn{3}{|l|}{ Health facilities } \\
\hline DASH & 406 & 52.6 \\
\hline General Hospital Akwanga & 160 & 20.7 \\
\hline Medical Center Mararaba Gurku & 206 & 26.7 \\
\hline \multicolumn{3}{|l|}{ Marital status } \\
\hline Single & 12 & 1.6 \\
\hline Married & 760 & 98.4 \\
\hline \multicolumn{3}{|l|}{ Religion } \\
\hline Christianity & 389 & 50.4 \\
\hline Islam & 383 & 49.6 \\
\hline \multicolumn{3}{|l|}{ Educational level } \\
\hline None & 32 & 4.1 \\
\hline Primary & 83 & 10.8 \\
\hline Secondary & 319 & 41.3 \\
\hline Tertiary & 338 & 43.8 \\
\hline
\end{tabular}
whereas 151 (19.6\%) were completely unemployed Table 1.

Table 1: Socio-demographic characteristics of study participants 


\begin{tabular}{lll}
\hline Variables & Frequencies $\mathbf{~}$ & Percentages \% \\
\hline Place of residence & & \\
Rural & 124 & 16.1 \\
Urban & 648 & 83.9 \\
Occupation & & \\
Unemployed & 151 & 19.6 \\
Civil servant & 117 & 15.2 \\
Business & 325 & 42.1 \\
Farmer & 13 & 1.7 \\
Others & 166 & 21.5 \\
Total & 772 & 100.0 \\
\hline
\end{tabular}

The mean age of this study population is $27.9 \pm 10.6$ years

\section{Assessment of patient's knowledge on Insecticide Treated Nets}

Knowledge of insecticide treated nets among the participants revealed that most, 707 (91.6\%) have heard or have knowledge of insecticide treated net. Similarly, most 538 (69.7\%) participants said healthcare workers emphasize the use of insecticide treated net when they attend antenatal care, and $432(56.0 \%)$ owned an insecticide treated net at home.

On the number of household members of the participants assessed, about a third each of the participants have $3-4[241(31.2 \%)]$ and $5-6$ [233 (30.2\%)] household members respectively. Only $42(5.4 \%)$ of the participants in this study have $>10$ household members.

About half $382(49.5 \%)$ have $1-2$ ITN at home, while $61(8.7 \%)$ had 3 or more ITN in their household.

Assessment of usage of insecticide treated nets showed that, $451(58.4 \%)$ sleeps inside an insecticide treated net, with 334 (74.1\%) sleeping in it daily while 117 (25.9\%) occasionally sleeps in ITN Table 2.

Table 2: Assessment of patient's knowledge on Insecticide Treated Nets (ITN)

\begin{tabular}{|c|c|c|}
\hline Ownership, Knowledge and Use of ITN & Frequencies n & Percentages $\%$ \\
\hline \multicolumn{3}{|l|}{ Prior knowledge of ITN } \\
\hline Yes & 707 & 91.6 \\
\hline No & 65 & 8.4 \\
\hline \multicolumn{3}{|c|}{$\begin{array}{l}\text { Do healthcare workers emphasize the use of ITN when you } \\
\text { attend antenatal care? }\end{array}$} \\
\hline Yes & 538 & 69.7 \\
\hline No & 234 & 30.3 \\
\hline \multicolumn{3}{|l|}{ Ownership of ITN } \\
\hline Yes & 432 & 56.0 \\
\hline No & 340 & 44.0 \\
\hline \multicolumn{3}{|l|}{ Number of household members } \\
\hline $1-2$ & 91 & 11.8 \\
\hline $3-4$ & 241 & 31.2 \\
\hline $5-6$ & 233 & 30.2 \\
\hline $7-8$ & 119 & 15.4 \\
\hline $9-10$ & 46 & 5.9 \\
\hline$>10$ & 42 & 5.4 \\
\hline \multicolumn{3}{|l|}{ Number of ITN clients have } \\
\hline None & 329 & 42.6 \\
\hline $1-2$ & 382 & 49.5 \\
\hline $3-4$ & 48 & 6.3 \\
\hline $5-6$ & 9 & 2.0 \\
\hline $7-15$ & 4 & 0.4 \\
\hline \multicolumn{3}{|l|}{ Use of ITN } \\
\hline Yes & 451 & 58.4 \\
\hline No & 321 & 41.6 \\
\hline \multicolumn{3}{|l|}{ Frequency of usage } \\
\hline Daily & 334 & 74.1 \\
\hline Occasionally & 117 & 25.9 \\
\hline
\end{tabular}

ITN= Insecticide Treated Net

Practice and belief on Insecticide Treated Net

Reasons for lack of usage was assessed and most said they are not using it due to heat 137 (30.4\%), due to smell 
$83(18.3 \%)$ and others for no good reason $86(19.1 \%)$ respectively. Other reasons given are as stated in Table 3 below.

Concerning the duration of usage of insecticide treated net among participants, $36(8.0 \%)$ had used insecticide treated nets for less than 6 months, $164(36.3 \%)$ used ITN between 6 months and one year, 160 $(35.5 \%)$ between one year and five years and $91(20.2 \%)$ used ITN for more than five years.

Perceptions of the participants was assessed about insecticide treated nets and $320(71.0 \%)$ feel it is very good and useful in preventing malaria, $58(12.8 \%)$ said they were using it out of compulsion, $46(10.2 \%)$ prefer spray to insecticide treated net and $27(6.0 \%)$ said it is very uncomfortable to use Table 3.

Table 3: Practice and belief on Insecticide Treated Net

\begin{tabular}{lll}
\hline Variables & Frequencies n & Percentages \% \\
\hline Reasons for non usage of ITN & 32 & 7.1 \\
Its itchy & 137 & 30.4 \\
Due to heat & 23 & 5.1 \\
No space to hang it & 83 & 18.3 \\
It smells & 15 & 3.3 \\
It is bad & 24 & 5.4 \\
Not comfortable & 33 & 7.3 \\
No idea of it use & 18 & 4.0 \\
It has expired & 86 & 19.1 \\
No reason & & 8.0 \\
Duration of use & 36 & 36.3 \\
Less than 6months & 164 & 35.5 \\
6 months to one year & 160 & 20.2 \\
1 to 5 years & 91 & \\
Above five years & & 71.0 \\
What is your opinion about insecticide treated net & 320 & 12.8 \\
Very good in preventing mosquito bite / malaria & 58 & 10.2 \\
Using it because they were mandated to use it & 6.0 \\
Prefer spray to insecticide treated nets & 46 & 100.0 \\
It is very uncomfortable to use & 27 & \\
Total & 451 & \\
\hline
\end{tabular}

\section{Discussion}

This study revealed that most participants know that insecticide treated net do prevent mosquito bites and malaria. More than half are aware of the ITN and are using it. Among the users, more than two-third used it efficiently. Factors contributing to non usage or inefficient use by some responders were the perceived heat it generates and the chemical smell from the ITN.

The mean age of the study participants was $27.9 \pm 10.6$ years comparable to the report by Babalola et al ${ }^{14}$ in Kaduna among women $29.3 \pm 6.2$ years. Both studies were among women of reproductive age group $(15-49$ years).

The present study showed that $91.6 \%$ have heard and are aware of the insecticide treated net, comparable to the $93.2 \%$ and $96 \%$ reported in other studies. ${ }^{14,15}$ This finding further validates the report of Ezire et al ${ }^{15}$ that was done across many states of Nigeria with Nasarawa State inclusive. While the similarity with the Babalola et al ${ }^{14}$ study in Kaduna could be due to the proximity of the two States and to the Federal Capital Territory Abuja. This avails the States with the enabling environment for Non Governmental Organizations, foreign partners and donors to provide the needed awareness on Malaria elimination strategies.

This study showed that slightly more than half of the participants $(56 \%)$ owned an insecticide treated net. This is better than the $28.8 \%$ reported by Ankomah et $a l^{16}$ in a population based survey in Nigeria. The varying study design with the present hospital based study may account for the difference, so also is the variation in time (over a decade). The relative higher level of education of the responders in this study where close to half are with tertiary level of education, may also be a contributor to the finding in this study. Our finding is lower than the $64.6 \%$ found by Ezire et al. ${ }^{15}$ Aside the time difference of ten years which may explain the difference, the varied study population of women of reproductive age only in the current study may also be a factor.

The prevalence of ITN utilization in this study of $58.4 \%$ falls short of the minimum standard global coverage target of $60 \%$ by 2015 . It is slightly higher than the $55.1 \%$ reported by Osuchukwu et al ${ }^{17}$ in Ogoja area of Cross River State. It is equally higher than the $40.68 \%$ reported by Komomo et al ${ }^{18}$ in Calabar. Both studies were in Cross River state in South-south Nigeria, with the discrepancies in climate, culture and beliefs a possible reason for the observation. It is far higher than the $19.2 \%$ reported by Ezire et $a l^{15}$, in a multi-state population based study among males and females. 
More than two - third $(74.1 \%)$ of this study population sleeps under the ITN daily. Our finding is very similar to the $74 \%$ reported in Kaduna. ${ }^{14}$ It is higher than the $24.3 \%$ found by Osuchukwu and his colleagues. ${ }^{17}$ Geographical similarity and difference with the cited study could explain the finding.

Reasons for the non utilization or the inconsistency in the ITN use were largely due to heat and the smell of chemical from the net. Similar finding was reported in another study. ${ }^{17}$ The fear of a possible hazard to the health of its users as well as the discomfort are plausible reasons for the finding.

\section{Conclusions}

The prevalence of Insecticide Treated Net (ITN) awareness in this study was $91.6 \%$. Ownership of insecticide treated net was $56.0 \%$ while its utilization from this study was $58.4 \%$. The prevalence of participants sleeping consistently under ITN among its users was $74.1 \%$. Reasons for non usage or inconsistence use of ITN were heat $(30.4 \%)$ and smell $(18.3 \%)$ of chemical emanating from the nets. More than two-third $(71 \%)$ of the responders in this study believed that ITN is useful in preventing mosquito bites and malaria.

\section{References}

1. WHO. World malaria report 2017. Geneva: World Health Organization; 2017. [Google Scholar

2. Ogun SA. Management of malaria. Nigerian Medical Practitioner Journal. 2006; Vol. 49(5): 94 -101.

3. Maternal Health in Nigeria: A Situation Update (2016) available at www.aphrc.org/publications/maternalhealth-nigeria-situation-update/.

4. Stewart T, Marchand RP. Factors that affect the success and failure of Insecticide Treated Net Programs for malaria control in SE Asia and the Western Pacific. WHO - WPRO; 1 - 36.

5. Owen Nkoka, Ting-Wu Chuang, Kun-Yang Chuang, Yi-Hua Chen. Factors associated with insecticidetreated net usage among women of childbearing age in Malawi: a multilevel analysis. Malaria Journal. 2018; $17: 372-387$.

6. Akinleye SO, Falade CO, Ajayi IO. (2009). Knowledge and Utilization of Intermittent Preventive Treatment for Malaria among Pregnant Women Attending Antenatal Clinics in Primary Health Care Centers in Rural Southwest Nigeria: A Cross - Sectional Study. Biomedical central pregnancy and childbirth. 2009; 9 (28): 1471 - 1493.

7. Chukwuocha UM. Dozie IS, Onwuliri CO, Ukaga LN, Nwoke BE, Nwankwo BO, Nwaokoro JC. Perceptions on the use of insecticide treated nets in parts of Imo River Basin, Nigeria: Implications for preventing malaria in pregnancy. African Journal of Reproductive Health. 2010;14:117 - 128.

8. Auta A. Demographic Factors Associated with Insecticide Treated Net use among Nigerian Women and Children. North American Journal of Medical Sciences. 2012; 4: 40 - 44.

9. National guidelines and strategies for malaria prevention and control during pregnancy. A publication of the Federal Ministry of Health. Nigeria malaria control programme. Abuja : FMOH. (2005)

10. Marchant T, Schellenberg JA, Edgar T, Nathan R, Abdulla S. Socially marketed insecticide-treated nets improve malaria and anaemia in pregnancy in southern Tanzania. Tropical Medicine International Health. 2002; 7: 149 - 158.

11. Okoye CA, Isara AR. Awareness on the use of Insecticide treated nets among women attending antenatal clinic in a tertiary health facility in Nigeria. Nigeria Medical Practitioner Journal. 2011; 52 (2):67 - 70.

12. Wagbasoma VA, Aigbe EE. ITNs Utilization among pregnant women attending ANC in Etsako West LGA, Edo state. Niger Journal of Clinical Practice. 2010; 13(2):144 - 148.

13. Yusuf OB, Dada-Adegbola HO, Ajayi IO, Falade CO. Malaria prevention practices among mothers delivering in an urban hospital in south west Nigeria. Journal of Vector Borne Diseases. 2008; $45: 217$ 224.

14. Babalola OJ, Sambo MN, Idris SH, Ajayi IO, Ajumobi O, Nguku P. Factors associated with utilization of LLINs among women of child-bearing age in Igabi, Kaduna State, Nigeria. Malaria Journal. 2019; 18: 412 -420 .

15. Ezire O, Adebayo SB, Idogho O, Bamgboye EA, Nwokolo E. Determinants of use of insecticide-treated nets among pregnant women in Nigeria. International Journal of Women's Health. 2015; 7: 655 - 661.

16. Ankomah A, Adebayo SB, Arogundade ED, Anyanti J, Nwokolo E, Ladipo O et al. Determinants of insecticide-treated net ownership and utilization among pregnant women in Nigeria. BMC Public Health. 2012; 12: $105-114$

17. Osuchukwu NC, Eko JE, Ochei KC, Okpe AE, Asuquo OD. Utilization of insecticide treated net and intermittent preventive treatment among pregnant women in Ogoja Local Government Area, Cross River State, Nigeria. Journal of Health, Medicine and Nursing. 2017; 39: 72 - 79.

18. Komomo EA, Egena R, Irene C, Ayorinde AO, Agada PO. Assessment of the utilization of the insecticide treated nets (ITNs) in Calabar metropolis, Cross River State, Nigeria. Journal of Health, Medicine and Nursing. 2016; 26: 196 - 205. 